\title{
PROPOSAL OF A SIMPLE METHOD FOR ASSESSING THE SUSCEPTIBILITY OF NATURALLY DEPOSITED CLAY GROUNDS TO LARGE LONG-TERM SETTLEMENT DUE TO EMBANKMENT LOADING
}

\author{
Motohiro INAGAKi ${ }^{\text {i) }}$, MASAKI NAKANO ${ }^{\text {ii) }}$, TOSHIHIRo NODA ${ }^{\text {ii), }}$ \\ Mutsumi TASHiro ${ }^{\text {iii) }}$ and AkIRA Asaoka ${ }^{\text {ii) }}$
}

\begin{abstract}
A simple method that utilizes the results of laboratory tests has been proposed for determining the susceptibility of soft clay grounds to large residual consolidation settlement due to embankment loading. It was found that there is a possibility of large long-term settlement if the sensitivity and compression index ratios of the clay material that constitutes the ground are equal to or more than 8.0 and 1.5, respectively. The compression index ratio is defined in this paper as the ratio $(\mathrm{Cc} / \mathrm{Ccr})$ of the steepest gradient of the compression curve of an undisturbed sample to that of the remolded sample. Through the SYS Cam-clay model, an elasto-plastic constitutive model that describes the actions of the soil skeleton structure, it was found that clays with large sensitivity and compression index ratios are characterized by initially highly structured soils and that decay/upgradation of the structure can easily occur due to plastic deformation. In addition, by following Schmertmann's graphic method for in-situ compression curve (1953), this paper proposes a method of deducing the in-situ initial conditions from the results of laboratory consolidation tests on undisturbed samples. These investigations revealed not only that large delayed settlement is facilitated in clays, which have higher degrees of structure and faster rates of structural decay, but also that the $\Delta \mathrm{e}$ method and other simple methods of predicting settlement may underestimate the amount of settlement.
\end{abstract}

Key words: clay, (compressive index ratio), (sensitivity ratio), soil structure, (SYS Cam-clay model) (IGC: E2)

\section{INTRODUCTION}

There are approximately 50 sites at which embankments for highways have been constructed on soft ground by the former Japan Highway Public Corporation. In about $20 \%$ of these sites there has been a problem with a residual settlement of $1 \mathrm{~m}$ or more after the entry of service. For example, about $2 \mathrm{~m}$ of settlement was predicted before embankment construction at the Kanda site (near the Hitachi Minami Oota Interchange on the Joban Expressway). However, since the entry of service, more than 20 years ago, it has continued gradually, resulting in as much as $4 \mathrm{~m}$ of settlement to date. Because of this, maintenance and repair work have been carried out repeatedly for such things as rectifying level differences, expanding the road shoulders, and repairing neighboring facilities. The accumulated cost of this work has been about 2 billion yen in the past 14 years, which works out to be as much as 900 million yen per meter of road.

Usually, embankments for soft grounds are designed in the following manner. First, the stability of the system is evaluated by determining whether the ground can sustain the load of the embankment without failing. Once confirming that the ground will not fail, the deformation of the ground due to the load of the embankment is calculated in order to examine whether the embankment will undergo any functional disorder. This method of design is based on the thought that the ground is at most risk at the time of completion of embankment construction and that once the embankment has been constructed, the ground will become stronger with the passage of time because its density increases due to consolidation resulting from the compression caused by the dissipation of excess pore water. This design approach, however, is well-suited for sufficiently remolded normal consolidation soil. As such, in the case of naturally deposited clay grounds with developed skeleton structures, one may encounter ground behavior that cannot be foreseen by this design approach.

Using the soil-water coupled finite deformation analysis program GEOASIA (Asaoka et al., 1994; Asaoka and Noda, 2007; Noda et al., 2008) with the SYS Cam-clay model (Asaoka et al., 2002), which is an elasto-plastic constitutive model capable of describing the action of the soil skeleton structure (structure, overconsolidation and

Central Nippon Expressway Company Limited, Nagoya, Japan.

Professor, Department of Civil Engineering, Nagoya University, Nagoya, Japan.

iii) Research Associate, ditto (mutsumi@civil.nagoya-u.ac.jp).

The manuscript for this paper was received for review on July 8, 2009; approved on November 30, 2009.

Written discussions on this paper should be submitted before September 1, 2010 to the Japanese Geotechnical Society, 4-38-2, Sengoku,

Bunkyo-ku, Tokyo 112-0011, Japan. Upon request the closing date may be extended one month. 
anisotropy), the authors have clarified that large delayed and major consolidation settlements leading to large residual settlements similar to that mentioned at the Kanda site is caused by the decay of structure of highly structured naturally deposited clay (Asaoka et al., 2000; Noda et al., 2005). In other words, when highly-structured clay in-situ is subjected to large stress increases greater than the consolidation yield stress, a large amount of compression occurs because of the significant structural degradation. Furthermore, it has also been shown that because of the softening that co-occurs with plastic compression, the dissipation of excess pore pressure is delayed, resulting in the settlement being extended over a long period.

The large delayed settlement described above, however, does not always occur in soft clay grounds. In $80 \%$ of the sites mentioned earlier, residual settlement has been suppressed. The computer program mentioned above is effective in predicting whether or not large delayed settlement will occur in a ground. However, since it is not practical to carry out such computer calculations at all sites, a simple initial screening method is necessary for evaluations. This paper first sorts out the common trends at clay ground sites that have exhibited large residual settlement. This is accomplished by taking examples of actual highway embankments constructed on soft clay grounds and sorting out their soil profiles, the loading conditions, the actual amounts of settlement, and the results of laboratory tests with respect to each site. The primary aim of this paper is to propose a method of judging the susceptibility of clay to large delayed settlement by focusing attention on two indices that can be determined from relatively easy laboratory tests. These two indices are the compression index and sensitivity ratios.

The second aim of this study was to utilize the SYS Cam-clay model to explain, in terms of elasto-plastic mechanics, the distinctive features of clays in which a large amount of delayed settlement occurs. By paying attention to the action of the structure which governs the mechanical behavior of the clay, we examined how the settlement is affected by the degree of structure and the manner in which the structure changes.

Furthermore, by following Schmertmann's graphic method (1953), this paper proposes a method for deducing the initial conditions of in-situ clay with consideration to the disturbance due to sampling and to explain the mechanism of large residual settlement behavior through a comparison of the compressibilities of the in-situ clay with those of undisturbed samples in laboratory tests. Finally, a further aim is to use the soil-water coupled finite deformation analysis program GEOASIA to clarify the reason why the simple method of prediction of consolidation settlement (the $\Delta \mathrm{e}$ method) laid out in the former Japan Highways Public Corporation's design manual cannot be used to predict large delayed settlement.
Table 1. Outline of the sites investigated and actual residual settlement at each site

\begin{tabular}{c|c|c|c|c}
\hline $\begin{array}{c}\text { Site } \\
\text { (Layer) }\end{array}$ & $\begin{array}{c}\text { Height of } \\
\text { embankment } \\
(\mathrm{m})\end{array}$ & $\begin{array}{c}\text { Thickness of } \\
\text { soft clay layer } \\
(\mathrm{m})\end{array}$ & $\begin{array}{c}\text { Residual } \\
\text { settlement } \\
(\mathrm{cm})\end{array}$ & $\begin{array}{c}\text { Measuring point } \\
\text { after entry into } \\
\text { service (year) }\end{array}$ \\
\hline \multicolumn{5}{|l}{} \\
\hline 〈Small residual settlement〉 \\
\hline A & 5.7 & 30 & 30 & 20 \\
\hline B & 7.7 & 28 & 67 & 20 \\
\hline C & 7 & 23 & 38 & 20 \\
\hline D & 6.8 & 14 & 29 & 20 \\
\hline E & 6 & 13 & 55 & 20 \\
\hline F & 9 & 11 & 26 & 10 \\
\hline G & 10 & 10 & 3 & 10 \\
\hline
\end{tabular}

〈Large residual settlement〉

\begin{tabular}{c|l|l|l|l}
\hline $\mathrm{H}$ & 8 & 25 & 112 & 12 \\
\hline $\mathrm{I}$ & 9 & 16 & 188 & 16 \\
\hline $\mathrm{J}$ & 7.5 & 31 & 122 & 20 \\
\hline $\mathrm{K}$ & 5 & 22 & 200 & 25 \\
\hline
\end{tabular}

\section{ACTUAL RESIDUAL SETTLEMENT DUE TO EMBANKMENT LOADING OBSERVED IN THE SOFT CLAY GROUNDS}

Table 1 shows an outline of representative soft clay ground sites together with the actual conditions of settlement at each site due to embankment loading. The ground layer structures of these sites are illustrated in Fig. 1 using the symbols specified in JIS0051-2000, Method of Classification of Geomaterials for Engineering Purposes. The "thickness of the soft clay layer" shown in Table 1 is the sum of the thicknesses of the cohesive soil (Cs) and the organic soil (O; grey colored layer) in Fig. 1.

According to the former Japan Highways Public Corporation Design Guideline (Earthwork), grounds composed of soft layers (including loose sand layers) $15 \mathrm{~m}$ or thicker are classified as deep layer-type (Type III) grounds, where settlement is said to extend over long periods. The majority of sites mentioned in Table 1 belong to this deep layer type. It is evident from the values shown in the table that it is not possible to judge the extent of long-term residual settlement purely on the basis of the thickness of the soft clay layer.

Embankment loading on soft clay grounds may also cause stability problems in addition to settlement problems. If the soft clay layer is situated near the surface layer of the ground, stability problems occur often. Because of this, ground improvement measures, such as vertical drain method, are carried out in certain cases before the construction of an embankment. In the sites studied here, the sand drains methods was applied at Site-F and Site-K, while Site-G used a cardboard drain. The mass permeability improvement of the ground due to the drains promotes the consolidation settlement of the soft 


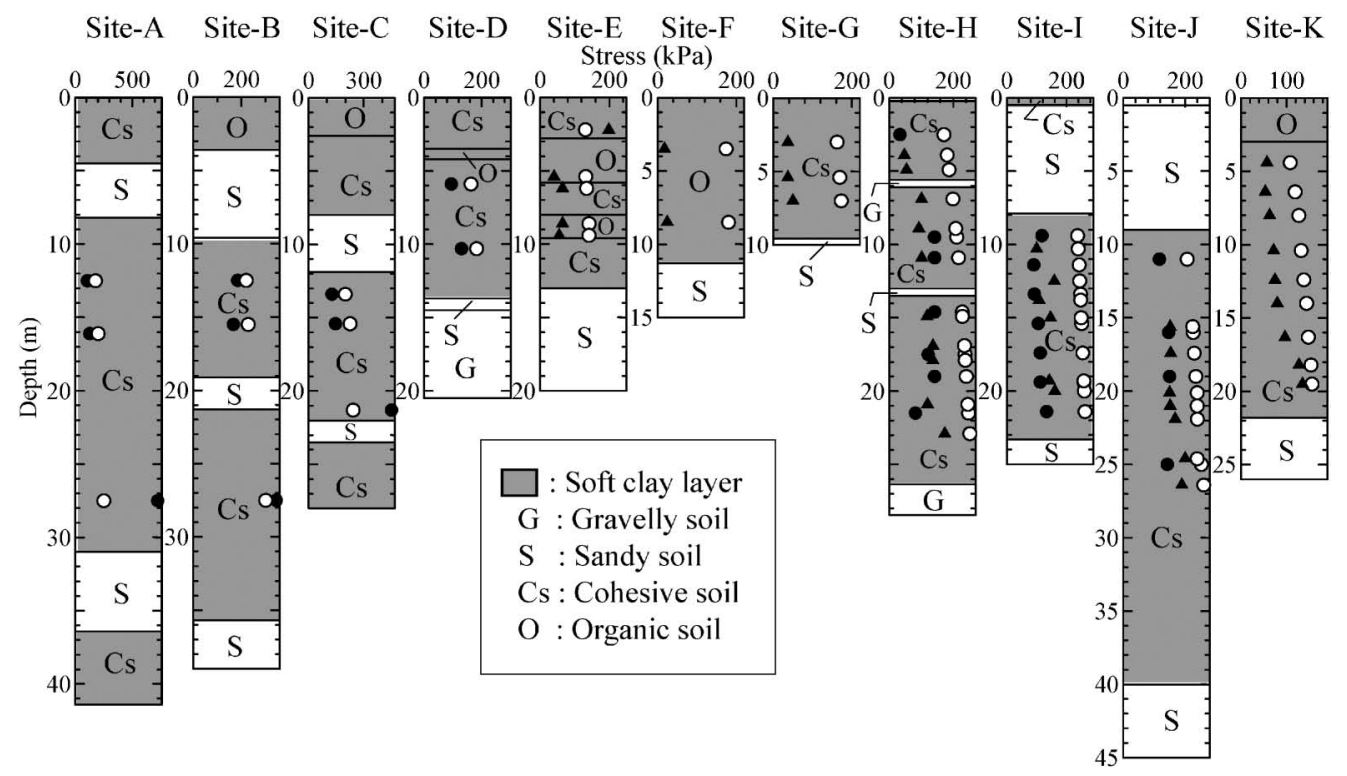

$O$ : Vertical effective stress after embankment loading (Initial effective overburden pressure + Amount of stress increase due to embankment loading) $(\mathrm{kPa})$

- Consolidation yield stress obtained from undisturbed specimens sampled before embankment construction $(\mathrm{kPa})$

$\boldsymbol{\Delta}$ : Consolidation yield stress obtained from undisturbed specimens sampled from the bare ground parts after the embankment was put into use $(\mathrm{kPa})$

Fig. 1. Histograms of the sites studied

clay layer. In cases like Site-F and Site-G, where the soft clay layer is only about $10 \mathrm{~m}$ thick and the drain effect extends over the entire soft clay layer, drains can be effective in significantly reducing residual settlement. At Site$\mathrm{K}$, however, the drain was placed to a depth of only $6 \mathrm{~m}$ from the ground surface despite the $22 \mathrm{~m}$ thick soft clay layer. As a result, the residual settlement reduction effect is seen to have been small.

As for the problem of settlement, the basic principle in the former Japan Highways Public Corporation Design Guideline was not to take countermeasures before embankment construction but to execute maintenance and repairs as necessary after the entry of service. Among the grounds with thick deposited soft clay layers, there are cases of naturally deposited clay grounds in which disturbance has caused decreases in strength. In such grounds, and especially in the case of those similar to Site-I and Site-J, which have experienced no stability problems because of the presence of a sand layer in the upper part of the ground, embankment loading without any prior ground treatment has produced large residual settlement.

The height/weight of the embankment also needs to be taken into consideration. The open circles in Fig. 1 indicate the vertical effective stress (initial effective overburden pressure + effective stress increase due to embankment loading as determined from Osterberg's Influence Chart, 1957) within the ground after embankment loading. The filled symbols denote the consolidation yield stress determined from oedometer tests carried out on un- disturbed specimens sampled at each depth. The filled circles represent the undisturbed specimens sampled before embankment loading from the ground directly beneath the embankment site. The filled triangles indicate those sampled from the bare ground parts near the embankment after the entry of service, where the effect of embankment loading is small. Taking account of the consolidation yield stress distributions at Site-H, Site-I, and Site-J in the direction of depth, it is assumed in this paper that the effect of sampling time and sampling location on the consolidation yield stress is small. Usually, little stress history is experienced by alluvial clay grounds due to such things as ground deformation during the deposition stage and erosion. Because of this, the initial effective overburden pressure is almost equal to, but slightly smaller than, the consolidation yield stress (i.e., the soil is in a slightly overconsolidated state) in most cases. As a result, in the sites studied here, the relatively large embankment loads due to tall embankments of at least $5 \mathrm{~m}$ in height cause the stress states to exceed the consolidation yield stress even in fairly deep locations of the soft clay layer. Apart from the clays in sites such as Site-F and Site-G, where the clay layers exist in a shallow part of the ground and the consolidation yield stresses are small, the embankment loading results in the clays of most sites being under stress levels slightly exceeding the consolidation yield stresses. From the above, it can be understood that it is not possible to judge the extent of residual settlement from only the stress levels. 


\section{METHOD OF JUDGING CLAYS SUSCEPTIBLE TO LARGE RESIDUAL SETTLEMENT THROUGH THE RESULTS OF CONVENTIONAL LABORATORY TESTS}

As explained above, it is not possible to judge the extent of residual settlement by only the thickness of a soft clay layer or by its stress level. In this section, the distinctive trends of soft clays that exhibit large residual settlement are determined by examining the results of laboratory tests commonly carried out at many sites, and criteria for assessing this type of clay are proposed. Attention was focused on parameters that are strongly related to the decay of structure because the large delayed settlement at the Kanda site on the Joban Expressway was caused by the structural decay of highly structured clay. In this study, the two parameters used for assessing the clays were 1) the sensitivity index, which can be obtained from unconfined compression tests, and 2) an original parameter defined in this study, called the compression index ratio, which can be determined from oedometer tests.

The gradient of the compression curve of an undisturbed sample becomes a maximum near stress levels just exceeding the consolidation yield stress, and large compression occurs at this stage. The majority of the soft clay sites studied here reach these stress levels due to embankment loading. For this reason, attention was paid to the steepest gradient immediately after exceeding the consolidation yield stress in the compression curves for the undisturbed samples. This is termed the compression index $C c$. In addition, attention was also paid to the gradient of the compression curve for remolded samples. This value was defined as $C c r$. Remolded samples refers to those that are obtained from undisturbed samples by sufficiently kneading them without changing the water content or after adding the proper quantity of water.

In actual practice, oedometer tests are rarely carried out on remolded samples. For this reason, $\mathrm{Ccr}$ was calculated in a unified manner from the liquid limit $w_{\mathrm{L}}$ (\%) us- ing the following empirical equation proposed by Skempton (1944).

$$
C c r=0.007\left\{w_{\mathrm{L}}-10\right\}
$$

In this paper, the value of $\mathrm{Cc} / \mathrm{Ccr}$ was defined as the compression index ratio (Fig. 2).

The sensitivity and compression index ratios of the soft clays at Site-A to Site-K investigated in this paper are shown in Figs. 3(a) and (b), respectively. According to Terzaghi and Peck (1967), clays with sensitivity ratios between 4 and 8 are classified as sensitive clays, whereas those with sensitivity ratios of 8 or higher are classified as extra-sensitive clays. In addition, clays with low or medium sensitivity ratios are expressed by the following equation.

$$
C c=1-1.3 C c r=0.009\left\{w_{\mathrm{L}}-10\right\}
$$

In other words, their compression index ratios are between 1 and 1.3. Furthermore, it has been shown that the compression index ratio is even greater in clays with extremely high sensitivity ratios and that Eq. (2) above can only estimate the lower limit of the amount of compres-

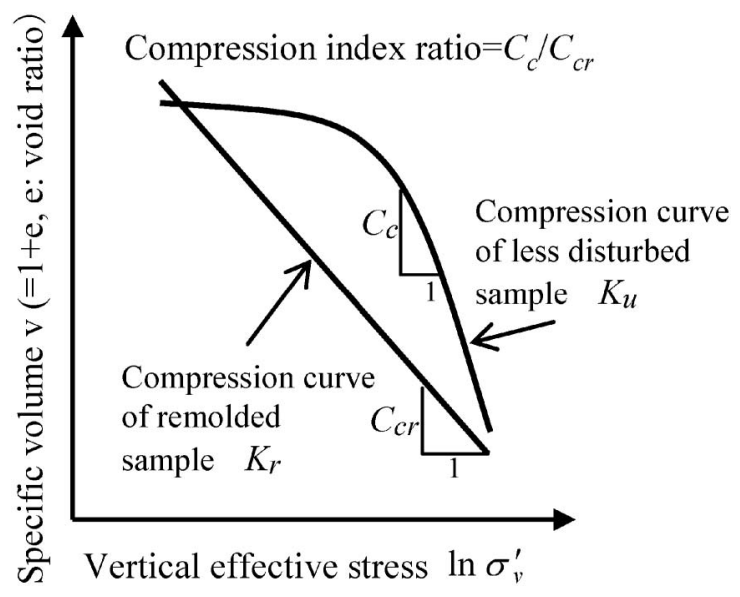

Fig. 2. Definition of the compression index ratio

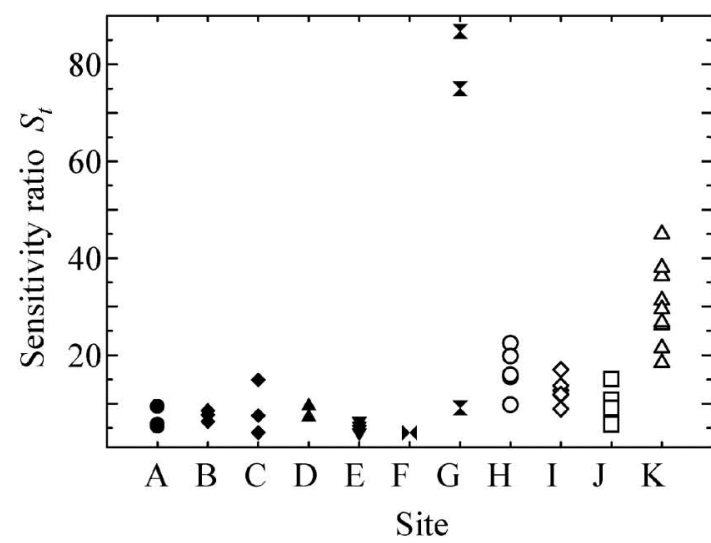

(a) Sensitivity ratio

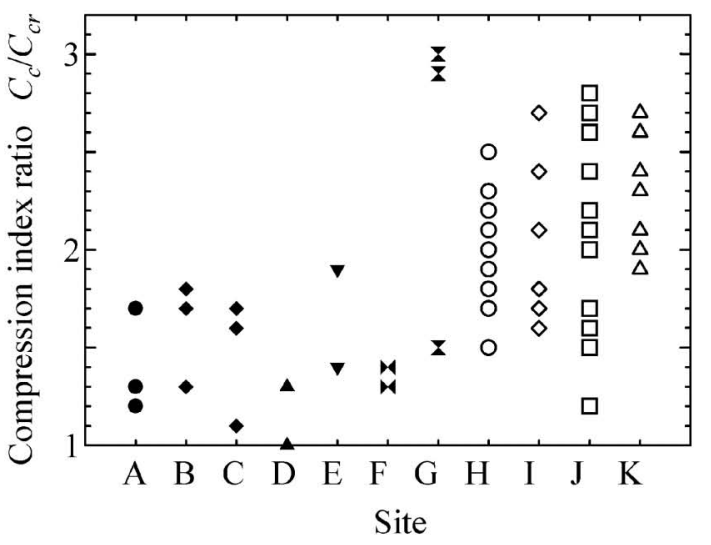

(b) Compression index ratio

Fig. 3. Characteristics of the soft clays at the sites investigated 


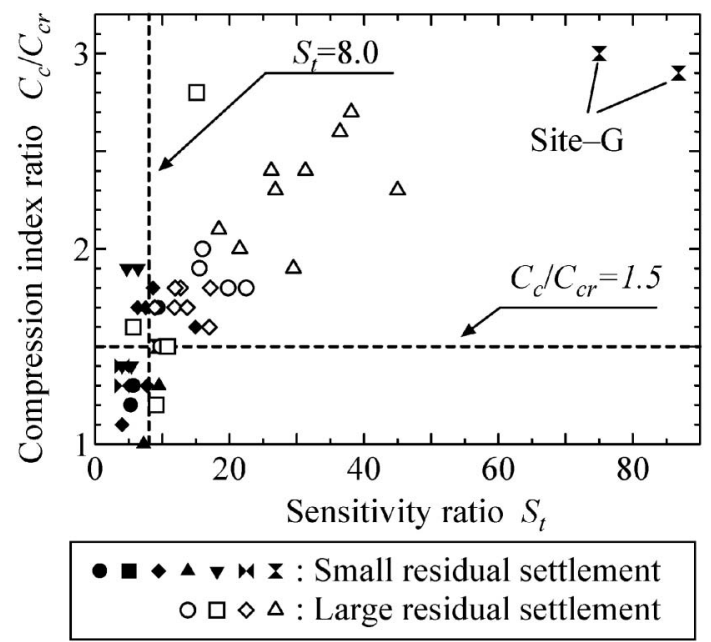

Fig. 4. Classification based on the sensitivity and compression index ratios

sion.

It can be noticed that among the clays in the sites investigated here, those in sites that exhibited large residual deformation have large sensitivity ratios and can be classified as extra-sensitive clays. At the same time, their compression index ratios are also large. With regard to samples whose sensitivity and compression index ratios were both determined, Fig. 4 classifies the extent of settlement at the respective sites on the basis of these two parameters. The figure indicates that, generally speaking, a compression index of 1.5 or greater and sensitivity ratio of 8 or greater, can be used as criterion to judge clays that exhibit large residual settlement. In the future, when a naturally deposited clay is encountered where the embankment load exceeds the preconsolidation stress, reference to the criterion shown in Fig. 4 will allow judgment of whether or not long-term large settlement is likely to occur.

The data for Site-G shown in Fig. 4 is for Ariake clay, which is a well-known extra-sensitive clay. As mentioned earlier, because of the stability problem due to the soft clay layer extending up to the vicinity of the ground surface, the embankment at Site-G was constructed after ground improvement by drain methods. As a result, consolidation of the soft clay layer was promoted, and settlement had mostly subsided before the entry of service. Consequently, the amount of residual settlement at this site is small.

In order to collate the test results in the manner mentioned above, it is necessary to use remolded samples to obtain test results that will become the criteria for defining the sensitivity and compression index ratios. Given that the compression curve (NCL) of remolded specimens samples defines the elasto-plastic parameters unique to the type of soil, it can be understood that remolded samples are defined as those in which the soil skeleton structure has been lost completely. The authors suggest that, as a rule, distinct methods for specimen preparation and testing on remolded samples should be specified and con- solidation tests should be performed on remolded specimens when designing embankments and other structures to be constructed on soft ground.

\section{INTERPRETATION OF THE MECHANICAL CHARACTERISTICS OF CLAYS SUSCEPTIBLE TO LARGE RESIDUAL SETTLEMENT THROUGH THE SYS CAM-CLAY MODEL}

As described above, clays that exhibit large residual settlement have a tendency to have high sensitivity and compression index ratios. The aim of this section is to explain this characteristic in the language of elasto-plastic mechanics through the use of the SYS Cam-clay model.

The compressibility and strength of soils are determined by the soil type and their soil conditions. In the SYS Cam-clay model, the type indicates the elasto-plastic parameters, which are non-dependent on the soil skeleton structure as well as the evolution parameters that determine how the soil skeleton structure changes. If the soil is saturated, the condition is defined by the void ratio, the amount of stress, and the degree of soil skeleton structure. Furthermore, remolded specimens and undisturbed specimens can be considered the same type of soil, the remolded specimens being in a state of having completely lost their soil skeleton structures. Therefore, expressing the compressibilities and strengths of remolded specimens and undisturbed specimens by the respective ratios (i.e., compression index and sensitivity ratios) can be interpreted to mean that the effects of the elasto-plastic parameters are eliminated, while the effects of the degree of the soil skeleton structure and how it changes (i.e., evolution parameters) are made more prominent.

In previous research studies (for example, Noda et al., 2005), the authors have shown that structure dominates the mechanical characteristics of naturally deposited clays even within the skeleton structure and that the delayed consolidation settlement behavior leading to large residual settlement is particular to clays with a high degree of structure. In the current study, special attention was paid to the degree of evolution of structure in the skeleton structure of the clays and the manner in which the structures change in order to investigate how these factors affect the sensitivity and compression index ratios.

Figures 5 and 6 show the effects of the initial degree of structure $\left(1 / R_{0}^{*}\right)$ and the structural decay rate (structural degradation index $a$ ) on the undrained shear behavior (assuming unconfined compression tests) and one-dimensional compression behavior (assuming oedometer tests), which were obtained through the responses of the SYS Cam-clay model in a uniform deformation field. The set of material constants shown in Table 2 for the clay of Site-I was used in these computations as the parameters representing conventional clay.

It can be observed from the figures that, with an increasing degree of initial structure (Fig. 5, 1/ $R_{0}^{*}$ : Large) and faster structural decay rate (Fig. 6, $a$ : Large), the peaks of undrained shear behaviors become high and the 


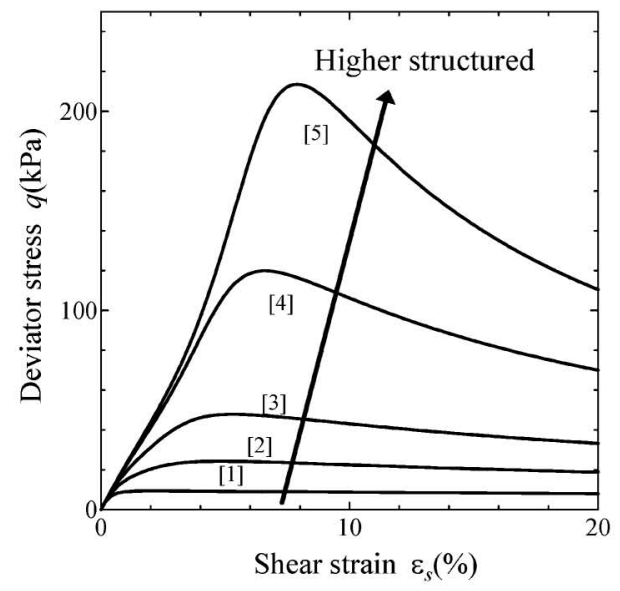

(a) Sensitivity ratio (undrained shear response)

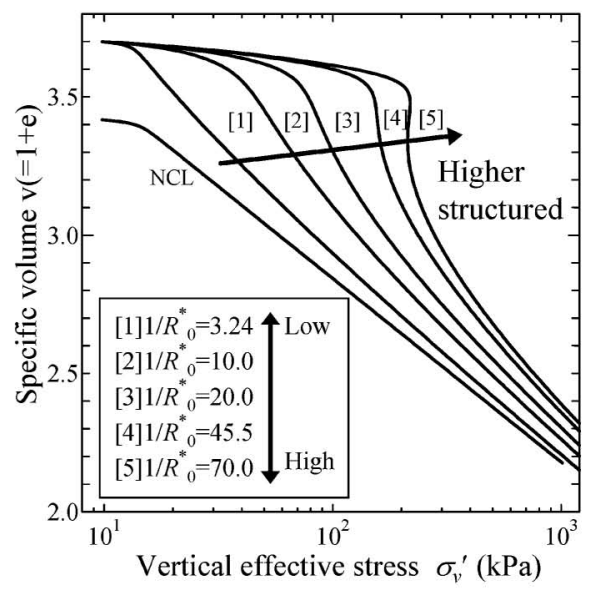

(b) Compressive index ratio (1-D compressive response)

Fig. 5. Effect of initial degree of structure $(a=0.22)$
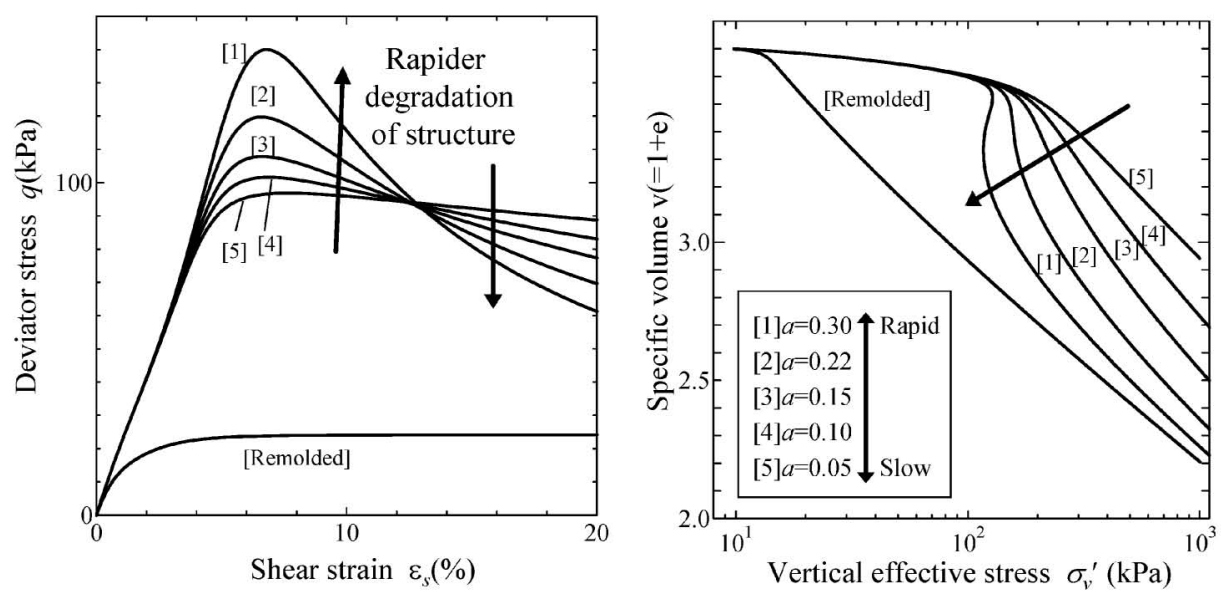

(a) Sensitivity ratio (undrained shear response) (b) Compressive index ratio (1-D compressive response)

Fig. 6. Effect of initial degree of structure $\left(1 / R_{0}^{*}=45.5\right)$

Table 2. Material constants used in the analysis (Site-I)

\begin{tabular}{c|l}
\hline \multicolumn{2}{|l}{ 〈Elasto-plastic parameters〉 } \\
\hline Compressive index $\tilde{\lambda}$ & 0.29 \\
\hline Swelling index $\tilde{\kappa}$ & 0.05 \\
\hline Critical state constant M & 1.90 \\
\hline NCL intercept N & 2.75 \\
\hline Poisson's ratio $v$ & 0.1 \\
\hline
\end{tabular}

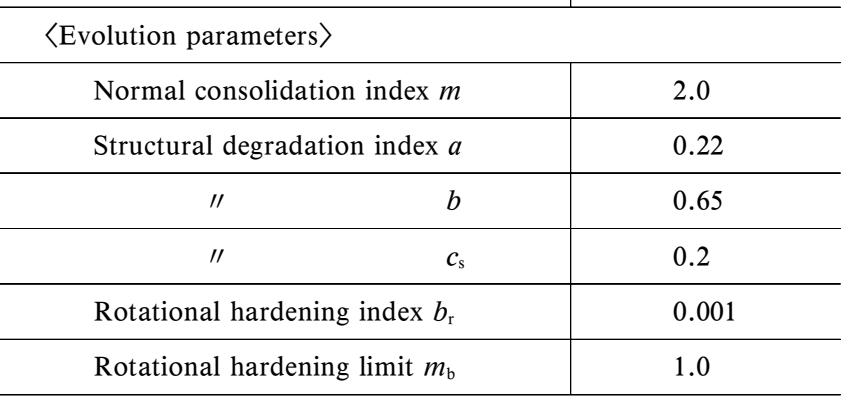

steepest gradients of the compression curves become large. In other words, it can be said that clays with large sensitivity and compression index ratios $\mathrm{Cc} / \mathrm{Ccr}$, which lead to large residual settlement, have high degrees of structure. In addition, such structures can evolve easily (i.e., structural decay/upgradation can occur easily).

In this study, the following equation is used as the evolution law that expresses structural decay/upgradation.

$$
\begin{aligned}
& \dot{R}^{*}=J U^{*}\left\{\left(1-c_{s}\right)\left(-D_{v}^{p}\right)+c_{s} \sqrt{\frac{2}{3}}\left\|D_{s}^{p}\right\|\right\}, \\
& U^{*}=\frac{a}{\mathrm{D}} R^{* b}\left(1-R^{*}\right)
\end{aligned}
$$

In the above equation, $D_{v}^{p}$ and $\left\|D_{s}^{p}\right\|$ indicate the volumetric component of plastic stretching and the deviator component of the Euclidian norm, respectively. In order to reproduce the experimental fact that structural decay in clay occurs more easily under compression than under shear, the value of $c_{s}$ is made small in the case of clay. In 
the present computations, the value of $c_{s}$ was taken as 0.2 . According to the above equation, the plastic swelling $\left(-D_{v}^{p}<0\right)$ caused by the loss of overconsolidation will produce structural upgradation $\left(R^{*} \rightarrow 0\right)$. Since loss of overconsolidation is faster than structural decay in clays, structural upgradation will occur before the peak in the case of undrained shear and before the consolidation yield stress in the case of one-dimensional compression. Furthermore, $a$, which determines the structural decay rate, influences not only the rate of structural degradation (decay) but also the rate of upgradation. Consequently, with increasing structural decay rates, structured overconsolidated clays, such as naturally deposited clay, exhibit larger sensitivity ratios (peak strengths) along with structural upgradation. Since the structural decay after this stage is also rapid, the compression index ratio also becomes large at the same time (in the case of evolution laws where only structural decay occurs, the compression index ratio becomes large at faster structural decay rates, but the sensitivity ratio decreases).

The evolution laws of the soil skeleton structure are important enough to be referred to as the 2 nd set of constitutive equations. However, with respect to structure, overconsolidation, and anisotropy that occur due to plastic deformation, evolution/loss of all three factors takes place simultaneously. Therefore, it is not possible to formulate evolution laws for each of these factors directly from the test results. However, the evolution law of structure shown in Eq. (3) is capable of explaining the high sensitivity and compression index ratio characteristics of the clays within the same framework. As such, it is effective as an evolution law that simulates the mechanical behavior of naturally deposited clays well.

\section{THE CONDITIONS THAT LEAD TO OCCURRENCE OF LARGE RESIDUAL SETTLEMENT BASED ON DEDUCTION OF IN-SITU INITIAL CONDITIONS}

As discussed in the preceding sections, clays exhibiting large residual settlement are characterized by the fact that they can be classified through laboratory tests as those with both high sensitivity and high compression index ratios. The SYS Cam-clay model also showed that these clays could be described as having high levels of structure and a structure can evolve easily. This section examines why it is difficult to predict in-situ large residual settlement in such types of clays.

When predicting the in-situ settlement that could occur, it is usually assumed that the undisturbed specimens sampled from the site are in the same condition as the insitu clay and that the compression characteristics of both are the same. The method of prediction ( $\Delta \mathrm{e}$ method) of consolidation settlement laid down in the former Japan Highway Public Corporation's Design Guideline is also one based on the above assumption. In this method, the compression curves of undisturbed specimens are used to calculate the amount of settlement by determining the amount of variation in the pore ratio with respect to the stress increase within the ground due to embankment loading. Although this simple method of prediction has shown a fair extent of accuracy in many sites, it has been known to underestimate the amount of settlement at times. In other words, although there are instances in which the compressibility of the in-situ clay is well reproduced by the compressibility of the undisturbed specimens determined through laboratory tests, there are other instances where the compressibility of the in-situ clay is greater. Large residual settlement occurs in the latter instance.

Samples used for laboratory tests experience complicated stress paths during sampling, removal from the sampling tube, specimen preparation, and setting-up on the testing machine. Therefore, although undisturbed specimens are the ones with little disturbance, some variation from the in-situ condition cannot be avoided. Furthermore, since disturbance is irreversible plastic deformation, it is impossible, in principle, to restore the specimens to their predisturbance condition. The soil type, however, is not changed by disturbance. Therefore, by taking into account the changes that take place due to disturbance, that is, by considering the laboratory test results of undisturbed specimens that were closest to the clays in-situ, the initial conditions and mechanical characteristics of the in-situ clay are deduced in this paper. In addition, the relative ease or difficulty of predicting settlement through laboratory test results is examined by comparing the compressibilities of the clays in-situ with those determined from laboratory tests on undisturbed specimens.

The initial conditions of the clays in-situ are deduced here by referring to Schmertmann's graphic method (1953) for the compression curves of in-situ sediments. According to this method, if the compression curve obtained for undisturbed specimens is similar to the curve $K u$ shown in Fig. 7, the compression curve $K$ in-situ is deduced in the following manner. First, it is assumed that the undisturbed specimen was set up on the testing machine without any change in the water content. Consequently, the pore ratio $\mathrm{e}_{0}^{\mathrm{a}}$ in the initial condition (point $\mathrm{B}^{\prime}$ ) of the laboratory test will be the same as that of the in-situ clay. Therefore, point $\mathrm{A}$, which is equivalent to the overburden pressure $\sigma_{\mathrm{v} 0}^{\prime}$, becomes the in-situ initial condition. Next, by assuming that the consolidation yield stress $p_{c}$ of curve $K u$ is equal to the consolidation yield stress of curve $K$, the point denoting the initial condition (point A) and that denoting the consolidation yield stress (point D) are joined by a line with a gradient equal to the gradient $C_{s}$ of the swelling line of curve $K u$. The in-situ compression curve $K$ is then obtained by joining the consolidation yield stress point (point D) and the point (point F) that lies on curve $K u$ and is equivalent to 0.4 times the initial pore ratio.

The details of this graphical method are given in the original publication (Schmertmann, 1953). The most important aspect of this method is point $\mathrm{D}$, which indicates the consolidation yield stress. Regarding the consolidation yield stress of the in-situ compression curve, although Schmertmann suggested a number of methods 


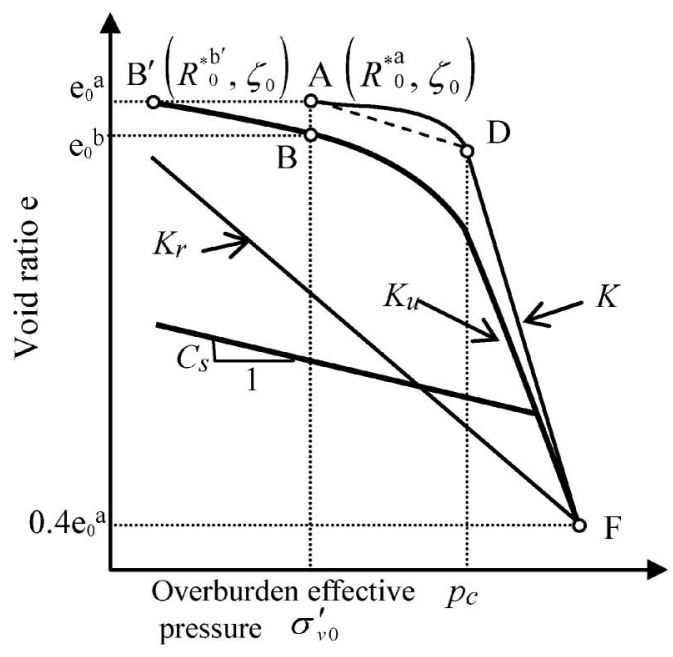

Vertical effective stress $\ln \sigma_{v}^{\prime}$

Fig. 7. Schmertmann's graphic method for compression curves of insitu sediments

for deducing it, he did not elaborate on it. In addition, he presented experimental evidence indicating that the consolidation yield stress decreases due to disturbance. However, unless the extent of disturbance that occurs from the sampling in-situ up to the time of commencing the laboratory test is known accurately, it is difficult to determine how much the consolidation yield stress of the in-situ clay has decreased compared with an undisturbed specimen. For this reason, in later studies (Terzaghi and Peck, 1967, etc.), the consolidation yield stress obtained from the compression curve $K u$ of the undisturbed specimen was applied just as it was to the compression curve $K$ of the in-situ clay.

For the sake of simplicity, the above graphical method was used in this study in order to deduce the in-situ initial conditions from the compression curves of undisturbed specimens and, from them, the compressibility characteristics. In the SYS Cam-clay model, the initial conditions are expressed by the specific volume $\left(\mathrm{v}_{0}\right)$, stress state $\left(\sigma_{\mathrm{v} 0}^{\prime}\right.$, $\left.K_{0}\right)$ and three soil skeleton structures ( $R_{0}^{*}$ (structure) $/ R_{0}$ (overconsolidation) $/ \zeta_{0}$ (anisotropy)). Given that point A in Fig. 7 denotes the initial condition of the clay in-situ, the specific volume $\mathrm{v}_{0}$ and vertical effective stress $\sigma_{\mathrm{v} 0}^{\prime}$ will be decided by it. As a general value for all clays, the lateral stress coefficient in-situ was assumed to be $K_{0}=0.5$ (stress ratio $\eta_{0}=0.75$ ), referring to the in-situ test results for the clays of Site-A, B, C and I shown in Table 2.

With regard to the soil skeleton structures, the compression curve of the in-situ clay was first determined so that it satisfied the condition that the consolidation yield stress of the undisturbed specimen and the in-situ clay was equal. The three soil skeleton structures were then obtained from the initial conditions. Since the above initial state quantities are related through Eq. (4), it becomes possible to determine each initial state quantitatively, in the case of clays, for example, if it is assumed that evolution/degradation of anisotropy are extremely
Table 3. Method for estimating initial in-situ state, considering disturbance during sampling

\begin{tabular}{c|c|c}
\hline \multicolumn{2}{c|}{ Initial in-situ state quantities } & Estimating method \\
\hline \multicolumn{2}{c}{ Specific volume v $(=1+\mathrm{e})$} & $\begin{array}{c}\text { Initial value in test of } \\
\text { "undisturbed" sample }\end{array}$ \\
\hline \multirow{3}{*}{$\begin{array}{c}\text { Stress } \\
\text { state }\end{array}$} & $\begin{array}{c}\text { Vertical effective } \\
\text { stress } \sigma_{\mathrm{v} 0}^{\prime}\end{array}$ & Effective overburden pressure \\
\cline { 2 - 3 } & $\begin{array}{c}\text { Lateral stress } \\
\text { coefficient } K_{0} \\
\left.\text { (stress ratio } \eta_{0}\right)\end{array}$ & $\begin{array}{c}\text { General value } K_{0}=0.5 \\
\left(\eta_{0}=0.75\right)\end{array}$ \\
\hline \multirow{3}{*}{$\begin{array}{c}\text { Skeletal } \\
\text { structure }\end{array}$} & \begin{tabular}{c} 
Anisotropy $\zeta_{0}$ \\
\cline { 2 - 3 }
\end{tabular} & $\begin{array}{c}\text { Structure } 1 / R_{0}^{*} \\
\text { Initial value in test of } \\
\text { "undisturbed" sample }\end{array}$ \\
\cline { 2 - 3 } & $\begin{array}{c}\text { Overconsolidation } \\
1 / R_{0}^{*}\end{array}$ & $\begin{array}{c}\text { Values which satisfy both the } 4 \\
\text { conditions above and the } \\
\text { consolidated state stress for an } \\
\text { "undisturbed" sample }\end{array}$ \\
\hline
\end{tabular}

slow characteristics. The method of estimating each initial in-situ state is shown in Table 3.

$$
\mathrm{N}-\mathrm{v}_{0}-\tilde{\lambda} \ln p_{0}^{\prime}-(\tilde{\lambda}-\tilde{\kappa}) \ln \left(\frac{\mathrm{M}^{2}+\left(\eta_{0}-\zeta_{0}\right)^{2}}{\mathrm{M}^{2}} \frac{R_{0}^{*}}{R_{0}}\right)=0
$$

The compression curves $K u$ of the undisturbed samples (indicated by [1]) determined assuming laboratory tests and the compression curves $K$ of the in-situ clay (indicated by [3]) deduced as described above are shown in Fig. 8 with respect to clays with slow and rapid structural decay rates and those that are highly structured and less structured initially. The compression curve NCL of clay that has lost its structure completely (indicated by [2]) is also shown in the same figure. Assuming the amount of stress increase in-situ due to embankment loading to be $\Delta \sigma_{\mathrm{v}}^{\prime}=$ $150 \mathrm{kPa}$ (corresponding to the mid-depth of the clay layer in Fig. 11), a comparison of the amount of compression after the initial overburden pressure (Fig. 8(a)) shows that, in the case of clays with high sensitivity and compression ratios (i.e., clays having highly developed structures as well as rapid structural decay rates), the in-situ compressibility is greater than that of the undisturbed sample, according to laboratory test results.

The compressibility of the clay at Site-J, where large delayed settlement occurred, is illustrated in Fig. 9(a). Initially, the compression curve of the undisturbed sample is in a bulky (highly structured) state compared with the remolded one. This bulky state is lost rapidly (decay is rapid) after the consolidation yield stress is reached. Because of this, the in-situ settlement was greater than that determined through laboratory tests on the undisturbed sample. On the other hand, in the case of Site-F, where no large delayed settlement occurred, even though the compression curve of the undisturbed sample is in a bulky (highly structured) state compared with the remolded one, loss of the bulky state does not occur easily (decay is slow) even after reaching the consolidation yield stress as illustrated in Fig. 9(b). Since the compressibilities of the undisturbed sample and the in-situ clay due to embankment loading are nearly equal, the amount of settlement predicted by laboratory tests on the 


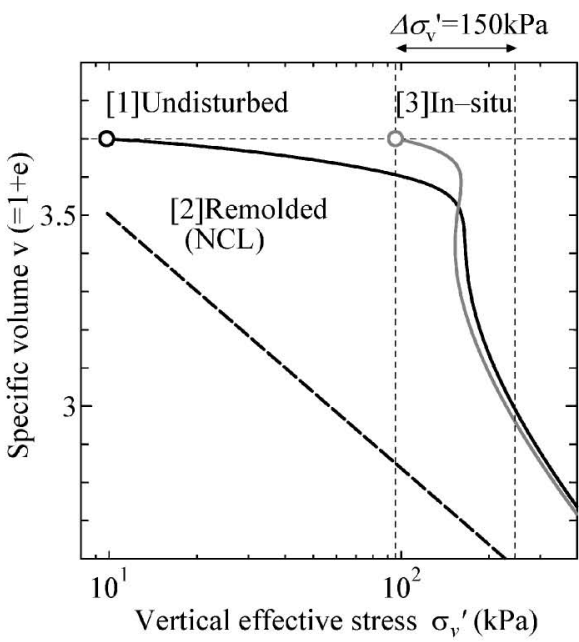

(a) Highly structured and rapid structural degradation ( $a=0.22,1 / R_{0}^{*}=50.0:$ Undisturbed, $1 / R^{*}=80.0:$ In-situ)

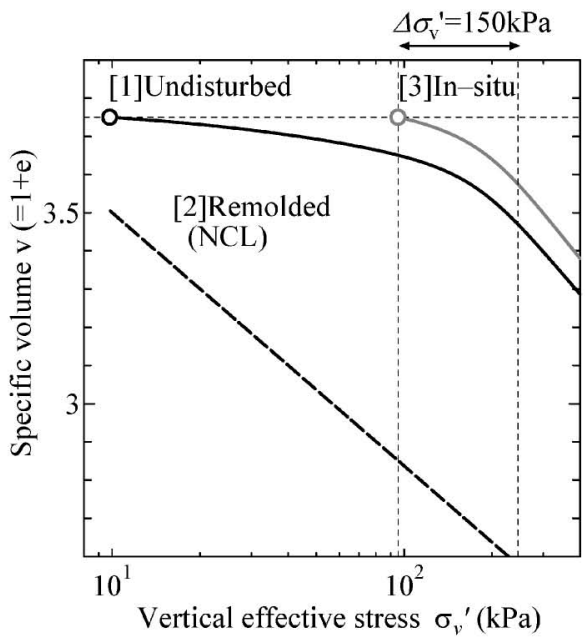

(c) Highly structured and slow structural degradation ( $a=0.05,1 / R^{*}=50.0:$ Undisturbed, $1 / R^{*}{ }_{0}=80.0:$ In-situ $)$

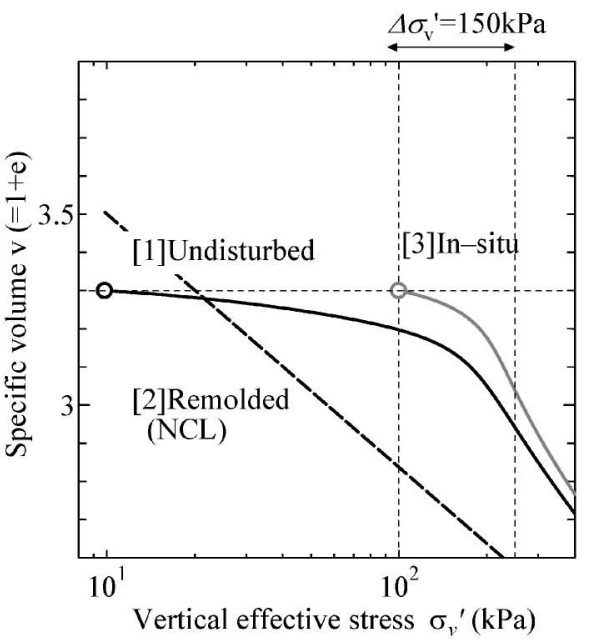

(b) Less structured and rapid structural degradation $\left(a=0.22,1 / R^{*}=8.0:\right.$ Undisturbed, $1 / R^{*}{ }_{0}=14.0:$ In-situ $)$

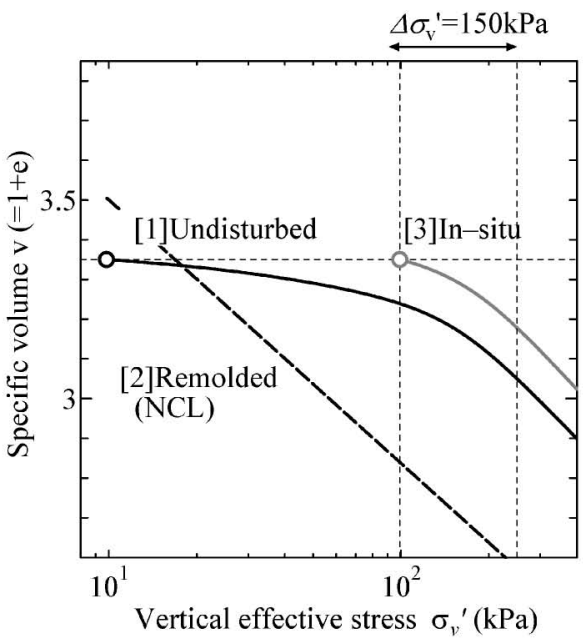

(d) Less structured and slow structural degradation $\left(a=0.05,1 / R_{0}^{*}=8.0:\right.$ Undisturbed, $1 / R^{*}=14.0:$ In-situ $)$

Fig. 8. Compressive behavior of "undisturbed" clay in-situ and in the laboratory

undisturbed sample agrees relatively well with the actual measured settlement. In the case of less structured clay too, the changes in the compressibilities before and after sampling are small because the effect of structural decay is primarily small. As a result, the amount of settlement predicted from laboratory tests on the undisturbed sample can be expected to have a tendency to agree well with the actual measured settlement.

In addition to the possibility of large delayed settlement occurring in highly structured clays with rapid structural degradation rates, there is also a possibility of underestimating the amount of settlement when simple methods of prediction, such as the $\Delta \mathrm{e}$ method, are used. Therefore, it is necessary to perform detailed calculations of the settlement using finite element analysis methods, etc. in designs concerning the settlement of this type of clay ground.

The results of unconfined compression tests on remolded and undisturbed samples of the clays in the two sites, described in Fig. 9(a) and (b) are presented in Fig. 10. In the case of highly structured clay with a rapid structural degradation rate such as the one in a, Site-J, the stressstrain curve of the undisturbed sample rises sharply in the initial stages, reaches the peak value of stress early, and shows a decrease in strength after that, as is shown in Fig. 10(a). On the other hand, in the case of highly structured clay which has a slow structural degradation rate, such as the one in b, Site-F, the stress-strain curve of the undisturbed sample rises very gradually but continuously without exhibiting a clear peak, as can be seen in Fig. 10(b). These characteristics also correspond well with the relationship to the structural degradation rate shown in Fig. 6(a).

\section{SOIL-WATER COUPLED BEHAVIOR OF THE FOUR TYPES OF CLAY DESCRIBED ABOVE}

Finally, the above discussion was confirmed through 


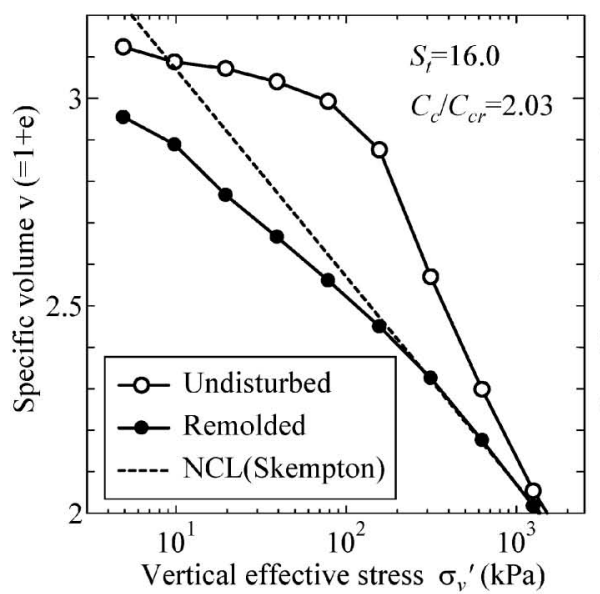

(a) Site-J (rapid degradation)

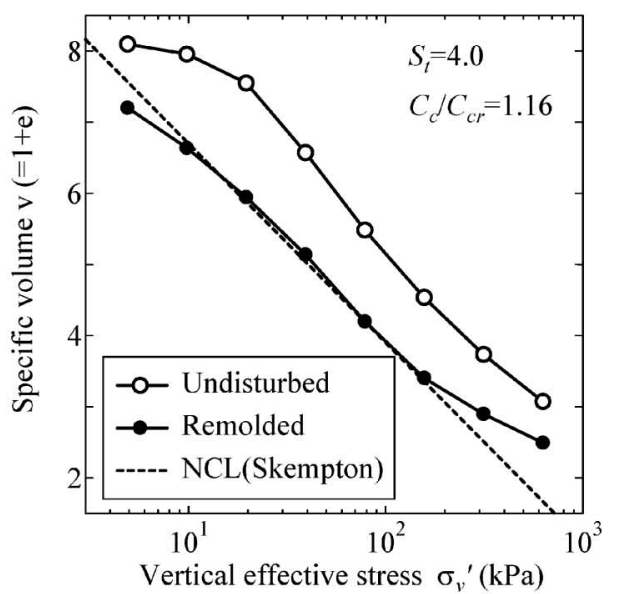

(b) Site-F (slow degradation)

Fig. 9. Comparison of compression curves

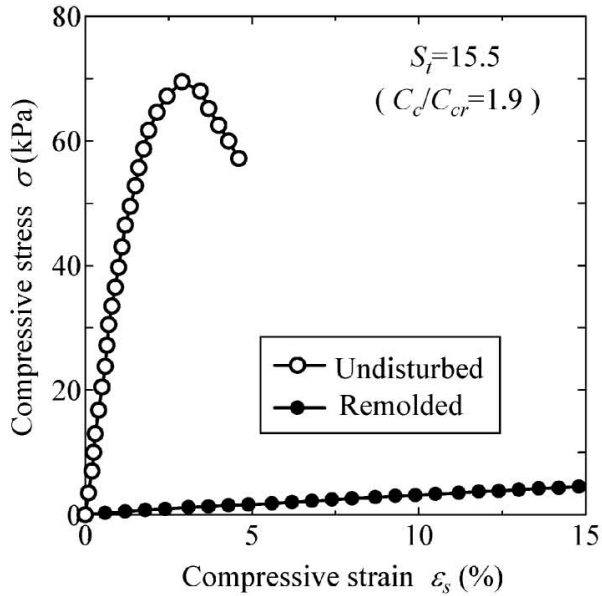

(a) Site-J (rapid degradation)

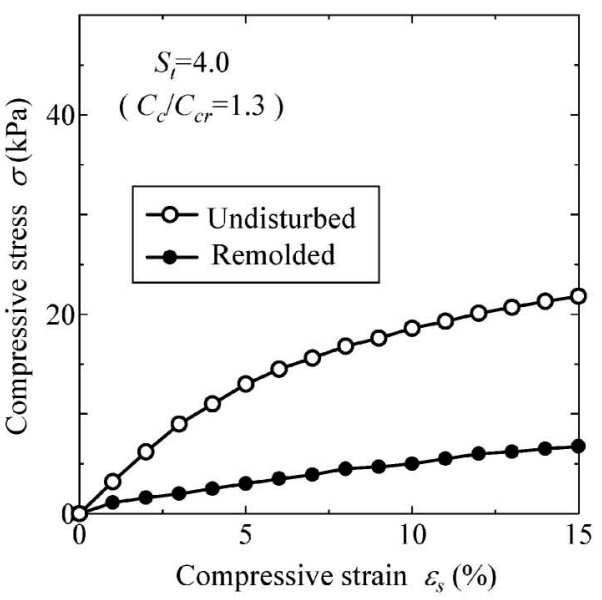

(b) Site-F (slow degradation)

Fig. 10. Comparison of unconfined compression behavior

soil-water coupled finite element deformation analysis utilizing the SYS Cam-clay model. The case of a ground (similar in ground structure to Site-I) consisting of a soft clay layer below a top sand layer and subject to a $10-\mathrm{m}$ embankment load is considered here (Fig. 11). The final amount of settlement calculated using the $\Delta \mathrm{e}$ method is considered to be the predicted value. It is compared here with the time-settlement relationship determined by soilwater coupled finite element deformation analysis, which is considered to be the actual measured value.

Table 4 shows the material constants and initial conditions used in the computations. It was assumed that the embankment was made up of very dense sand and that the sand layer was medium dense sand. The material constants assumed for the soft clay layer are the same as those shown in Table 2. As in the case of Fig. 8 above, four types of clays were considered: (a) initially highly structured clay with a rapid structural degradation rate, (b) initially less structured clay with a rapid structural degradation rate, (c) initially highly structured clay with a slow structural degradation rate, and (d) initially less structured clay with a slow structural degradation rate. To simplify the analysis, it was assumed that the specific volume, stress ratio, degree of structure, and degree of anisotropy were uniform along the direction of depth initially in both the clay and sand layers, and the initial overconsolidation ratios were distributed according to the overburden pressures.

In the soil-water coupled finite element deformation analyses, the embankment was represented by elastoplastic finite elements and by adding the finite elements to the ground as and when necessary. Since ground settlement progresses along with embankment loading, adjustments were made so that the crown of the embankment attained the specified height of $10 \mathrm{~m}$ at the time of completion of the embankment (120 days).

In calculating the settlement using the $\Delta \mathrm{e}$ method, the clay layer was divided into five 3-m thick layers, and the amount of settlement was calculated by hypothesizing the compression curves of undisturbed samples at the center 


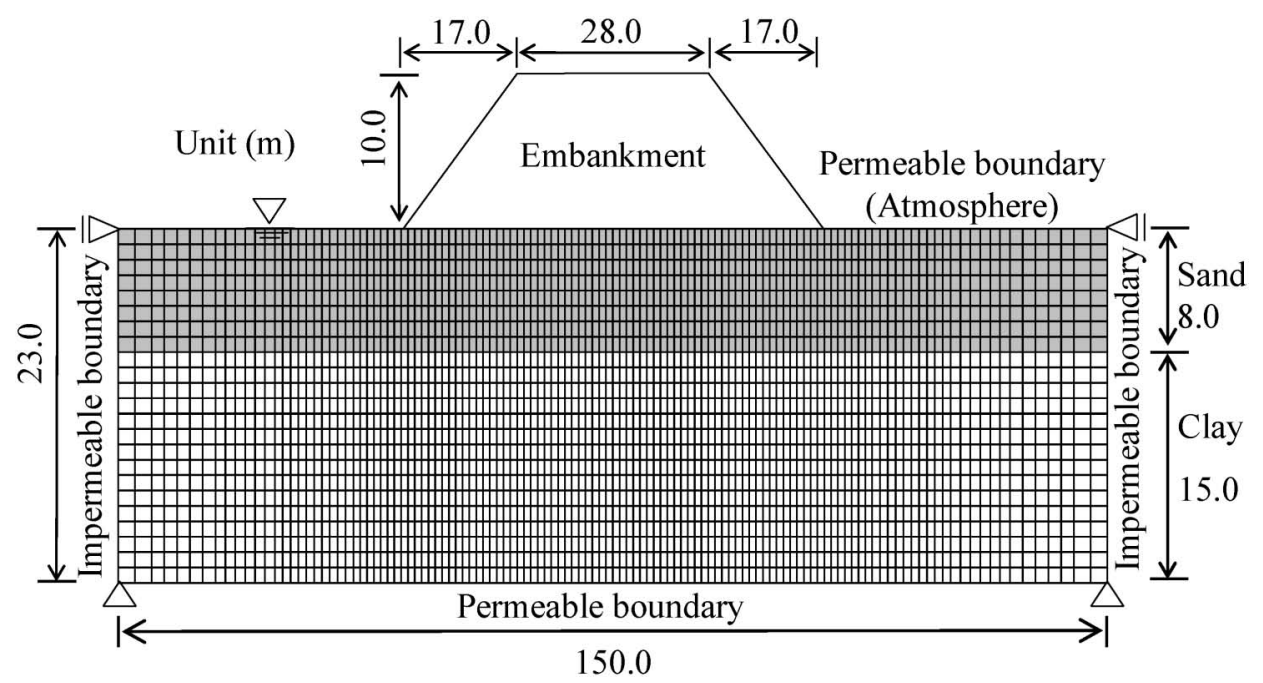

Fig. 11. Finite element mesh and boundary conditions

Table 4. Material constants and initial conditions used in the computations

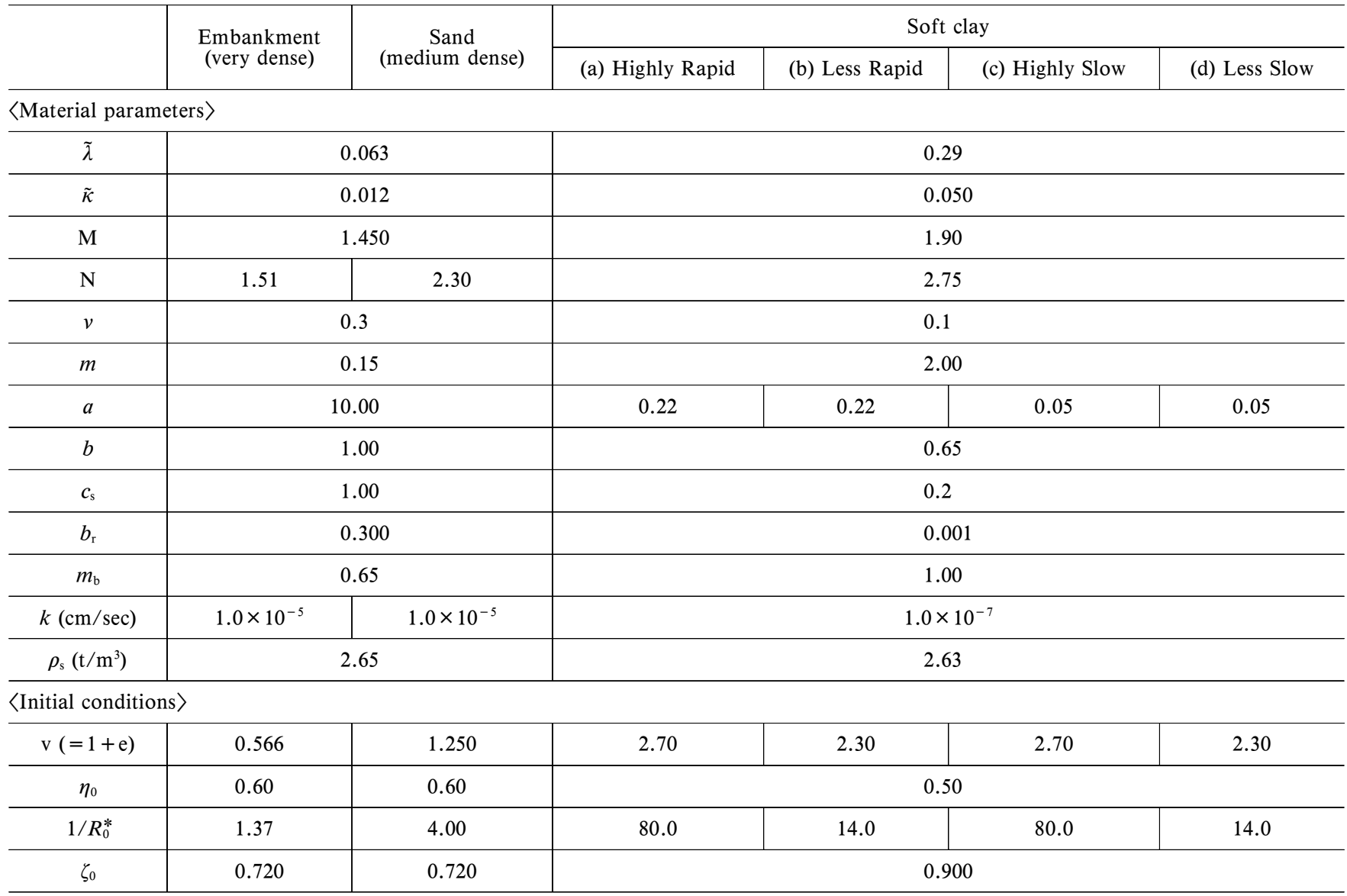

of each layer. The curves shown earlier in Fig. 8 correspond to the compression curves of the in-situ clay and undisturbed samples of the center of the third layer (counting from the top) of the clay layer.

In Fig. 12, which shows the amount of settlement directly below the center of the embankment, the dashed lines denote the predicted values (final amount of settle- ment obtained by the $\Delta \mathrm{e}$ method) and the solid lines denote the actual measured values (time-settlement relationship determined through soil-water coupled analyses utilizing the SYS Cam-clay model). The predicted value of the final amount of settlement is greater than the actual measured values in three cases, (b), (c), and (d). This difference can be attributed to the following three 


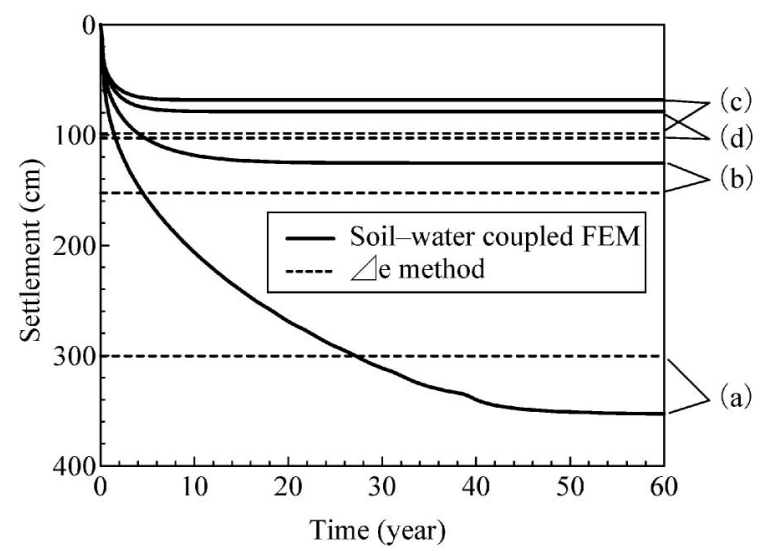

Fig. 12. Comparison of settlements computed using the $\Delta \mathrm{e}$ method and the soil-water coupled finite deformation method

factors. (1) Differences in the theories: the stress increases within the ground are based on elastic theory in the $\Delta \mathrm{e}$ method, whereas the soil is treated as an elasto-plastic material in the SYS Cam-clay model. (2) Differences in the stress paths: the $\Delta \mathrm{e}$ method presumes one-dimensional compression at all times, whereas the effects of soil-water coupling, such as a partially undrained state during loading and multi-dimensional compression during the period of constant load, appear in the case of soilwater coupled analyses. (3) Differences in the loading conditions: the distributed load application is instantaneous in the $\Delta \mathrm{e}$ method. Whereas, in soil-water coupled analyses, additional load such as overlay are applied according to the settlement. Whatever the case, the values predicted by the $\Delta \mathrm{e}$ method are on the safe side in the cases of (b), (c), and (d).

In contrast, although the differences in theories, stress paths, and loading conditions are the same as in the cases of (b), (c), and (d), there is a possibility that the in-situ settlement would be greater than that predicted by the $\Delta \mathrm{e}$ method in the case of (a), which is an initially highly structured clay with a rapid structural degradation rate. Moreover, although the conditions of permeability of the ground in all four cases, (a) to (d), are the same, settlement in the case of (a) accelerates during the constant load period, but gradual settlement continues over a very long period. This type of delayed consolidation settlement with acceleration of settlement is actually what has been observed at the Kanda site mentioned at the beginning of this paper. Further details and the mechanism of the above phenomenon have been described in other works by various authors (for example, Noda, et al., 2005).

\section{CONCLUSIONS}

From the construction records for embankments on soft ground of the former Japan Highway Public Corporation, the properties of soft clay grounds in which large long-term settlement occurred were sorted out, and a simple method of judging clays that are susceptible to large settlement was proposed. In addition, the characteristics of this type of clay were theoretically discussed using the SYS Cam-clay model. The main conclusions obtained through this study are as follows:

(1) A simple method of judging clays susceptible to large long-term settlement due to embankment loading was proposed. The proposed method makes use of two indices. There is a possibility of large long-term settlement occurring if the sensitivity and compression index ratios of the clay material that constitutes the ground are equal to or greater than 8.0 and 1.5 , respectively. The compression index ratio is defined by $\mathrm{Cc} / \mathrm{Ccr}$, where $\mathrm{Cc}$ is the steepest gradient of the compression curve of an undisturbed sample immediately after reaching the consolidation yield stress and $\mathrm{Ccr}$ is the gradient of the compression curve of the remolded sample. Because of the importance of these indices, the authors suggest that consolidation tests on remolded samples be performed when the design of structures to be constructed on soft ground is carried out.

(2) The SYS Cam-clay model, an elasto-plastic constitutive model that describes the actions of the soil skeleton structure, was used to discuss the two indices used in the above method of judgment. It was clarified that clays with high sensitivity and compression index ratios are characterized by high levels of structure initially and that further evolution of the structure can occur easily, i.e., decay/upgradation of the structure can occur easily.

(3) Referring to Schmertmann's graphic method for the compression curves of in-situ sediments (1953), a method of deducing the in-situ initial conditions from the results of laboratory consolidation tests on undisturbed samples was proposed. Computation of the compression curves of undisturbed samples and those of the in-situ clays through numerical analyses using the SYS Cam-clay model showed that the compressibilities of in-situ clay are only greater than those obtained assuming laboratory tests on undisturbed samples in the case of clays with both high levels of structure and rapid structural decay rates. These results show not only that large delayed settlement occurred in clays that have high levels of structure and rapid structural decay rates, but also that the $\Delta \mathrm{e}$ method and other simple methods of settlement prediction may underestimate the amount of settlement.

\section{REFERENCES}

1) Asaoka, A., Nakano, M. and Noda, T. (1994): Soil-water coupled behavior of saturated clay near/at critical state, Soils and Foundations, 34(1), 91-105.

2) Asaoka, A., Nakano, M., Noda, T. and Kaneda, K. (2000): Delayed compression/consolidation of natural clay due to degradation of soil structure, Soils and Foundations, 40(3), 75-85.

3) Asaoka, A., Noda, T., Yamada, E., Kaneda, K. and Nakano, M. (2002): An elasto-plastic description of two distinct volume change mechanisms of soils, Soils and Foundations, 42(5), 47-57.

4) Asaoka, A. and Noda, T. (2007): All soils all states all round geo- 
analysis integration, International Workshop on Constitutive Modeling-Development, Implementation, Evaluation, and Application, Hong Kong, China, 11-27.

5) Central Research Institute, Central Nippon Expressway Company Limited (2006): Soil Explorations Concerning the Properties of Clay Grounds (in Japanese).

6) Japan Highway Public Corporation (1975): Report on Soil Exploration of Douou Highway (Sapporo-Iwamizawa) between Higasinopporo and Toyohoro (in Japanese).

7) Japan Highway Public Corporation (1976): Report on the 2nd Soil Exploration of Douou Highway (Sapporo-Iwamizawa) Ebetsu Area (in Japanese).

8) Japan Highway Public Corporation (1998): Design Guideline (Sekkei youryou), Earthworks-Countermeasures for Soft Ground (in Japanese).

9) Japan Highway Public Corporation (2002): Study on Rational Design and Construction of Deep Mixing Method (2) (in Japanese).

10) Japan Highway Public Corporation (2004): Study on Dynamic Mechanical Characteristics of Soft Grounds (in Japanese).

11) Japan Highway Public Corporation (2005): Study on Dynamic Characteristics and Deformation of Soft Clays (in Japanese).

12) Noda, T., Asaoka, A., Nakano, M., Yamada, E. and Tashiro, M. (2005): Progressive consolidation settlement of naturally deposited clayey soil under embankment loading, Soils and Foundations, 45(5), 39-51.

13) Noda, T., Asaoka, A. and Nakano, M. (2008): Soil-water coupled finite deformation analysis based on a rate-type equation of motion incorporating the SYS Cam-clay model, Soils and Foundations, 48(6), 771-790.

14) Osterberg, J. O. (1957): Influences for vertical stresses in a semi-infinite mass due to an embankment loading, Proc. 4th ICSMFE, 1, 393-394.

15) Schmertmann, J. H. (1953): Estimating the true consolidation behavior of clay from laboratory test results, Proc. ASCE, 79(312), $1-26$.

16) Skempton, A. W. (1944): Notes On The Compressibility of Clays, Quart. J. Geol. Soc., London, C, 119-135.

17) Terzaghi, K. and B. Peck (1967): Soil Mechanics in Engineering Practice, 2nd edition, John Wiley \& Sons.

\section{APPENDIX 1: THE SUPER/SUBLOADING YIELD SURFACE (SYS) CAM-CLAY MODEL}

The Quantified Expression of Structure, Overconsolidation, Anisotropy, and Their Respective Evolution Rules

Naturally deposited soils, whether clayey or sandy, generally exist in a 'structured' and overconsolidated state. To describe the deformation behavior of a soil in this state, we have to start from the base of an elasto-plastic model of a de-structured soil in a state of normal consolidation. Given that a soil in this unstructured and normally consolidated state still possesses anisotropy, we take for our 'base' in this paper the corrected Cam-clay model of Roscoe and Burland (1968) with the introduced addition of the rotational hardening concept of Sekiguchi and Ohta (1977), which treats stress parameter $\eta^{*}$ and its evolution rule as an expression of anisotropy. The degrees of structure and overconsolidation are then introduced and quantified by means of the two concepts of the superloading surface for structure (Asaoka et al., 1998a, 2000, 2002), and the subloading surface for overconsolidation (Hashiguchi, 1978, 1989; Asaoka et al., 1997). That is to say, the degree of structure is expressed by means of a superloading surface situated on the outside of the Cam-clay normal-yield surface and similar to

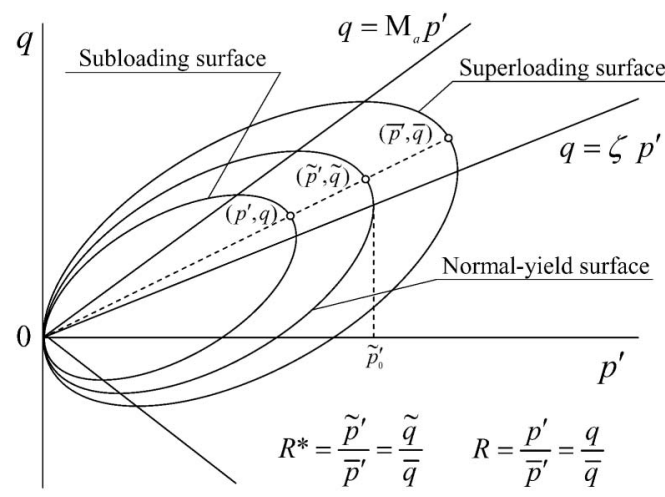

Fig. A1-1. Three loading surfaces

it (the center of similarity being the origin $p^{\prime}=q=0$ and the similarity rate being given by $R^{*}\left(0<R^{*} \leq 1\right)$, while the overconsolidation state is expressed by means of a subloading surface situated on the inside of the superloading surface and again similar to it (center of similarity $p^{\prime}=q=0$, similarity rate $R(0<R \leq 1)$; reciprocal $1 / R$ is the overconsolidation ratio). $p^{\prime}$ here is the mean effective stress and $q$ is the shear stress. Using effective stress tensor $\boldsymbol{T}^{\prime}$ (tension: positive), we can say: $p^{\prime}=-\operatorname{tr} \boldsymbol{T}^{\prime} / 3, q$ $=\sqrt{3 / 2 S \cdot S}$.

The closer $R^{*}$ is to 0 the higher the degree of structure, but with the loss of structure that accompanies the progressive plastic deformation $R^{*}$ will approach 1 (the evolution rule for $R^{*}$ ). Similarly, the closer $R$ is to 0 the more overconsolidated the state of the soil, but as $R$ increases toward 1 with plastic deformation, the state of the soil will also approach normal consolidation (the evolution rule for $R$ ). It can thus be assumed that the loss of structure with progressive plastic deformation brings a simultaneous release from overconsolidation (a transition to the normally consolidated state), resulting finally in conditions that match those in the Cam-clay model. The relative positions of the three loading surfaces, assuming conditions of axial symmetry, are as shown in Fig. (A1-1).

If we start from Cam-clay Eq. (A1-1) below as our base, given that the current effective stress exists on the subloading surface, we first need to adapt relations to the subloading surface through the application of various elasto-plastic principles such as the associated flow rule and Prager's consistency condition, so as to give Eq. (A1-2).

The Cam-clay potential:

$$
\begin{gathered}
\mathrm{MD} \ln \frac{\tilde{p}^{\prime}}{\tilde{p}_{0}^{\prime}}+\mathrm{MD} \ln \frac{\mathrm{M}^{2}+\eta^{* 2}}{\mathrm{M}^{2}}+\int_{0}^{t} J \operatorname{tr} D^{p} d \tau \\
=f\left(\tilde{p}^{\prime}, \eta^{*}\right)+\int_{0}^{t} J \operatorname{tr} D^{p} d \tau=0
\end{gathered}
$$

The subloading surface:

$$
f\left(p^{\prime}, \eta^{*}\right)+\mathrm{MD} \ln R^{*}-\mathrm{MD} \ln R+\int_{0}^{t} J \operatorname{tr} D^{p} d \tau=0
$$


Here, $\mathrm{D}=(\tilde{\lambda}-\tilde{\kappa}) / \mathrm{M} /\left(1+\mathrm{e}_{0}\right)$ is the dilatancy coefficient, and $\mathrm{M}, \tilde{\lambda}, \tilde{\kappa}$ and $\mathrm{e}_{0}$ are the critical state constant, compression index, swelling index, and initial void ratio. $J=$ $(1+\mathrm{e}) /\left(1+\mathrm{e}_{0}\right)$ (e is the void ratio at time $\left.t=t\right) . \quad-\int_{0}^{t} J \mathrm{tr}$ $D^{p} d \tau$ (compression: positive) corresponds to the plastic volumetric strain $\eta^{*}$, the expression of anisotropy, is obtained using the rotational hardening variable $\boldsymbol{\beta}$, from the calculation $\eta^{*}=\sqrt{3 / 2 \hat{\eta} \cdot \hat{\eta}}, \hat{\eta}=\eta-\beta, \eta=S / p^{\prime}, S=T^{\prime}+$ $p^{\prime}$ I. $\boldsymbol{\beta}=\mathbf{0}$ expresses a state of no anisotropy. In the present paper, the evolution rules for $R^{*}, R$ and $\beta$ are given by the following equations.

Evolution rule for $R^{*}$ :

$$
\begin{aligned}
\dot{R}^{*} & =J U^{*}\left\{c_{s} \sqrt{2 / 3}\left\|\mathbf{D}_{s}^{p}\right\|+\left(1-c_{s}\right)\left(-D_{v}^{p}\right)\right\}, \\
U^{*} & =\frac{a}{\mathrm{D}} R^{* b}\left(1-R^{*}\right)^{c}
\end{aligned}
$$

Evolution rule for $R$ :

$$
\dot{R}=J U\left\|D^{p}\right\|, \quad U=-\frac{m}{\mathrm{D}} \ln R
$$

Evolution rule for $\boldsymbol{\beta}$ :

$$
\stackrel{\circ}{\boldsymbol{\beta}}=J \frac{b r}{\mathrm{D}} \sqrt{\frac{2}{3}}\left\|\boldsymbol{D}_{s}^{p}\right\|\|\hat{\boldsymbol{\eta}}\|\left(m_{b} \frac{\hat{\boldsymbol{\eta}}}{\|\hat{\boldsymbol{\eta}}\|}-\beta\right)
$$

$\boldsymbol{D}^{p}$ here is the plastic stretching tensor, $\boldsymbol{D}_{s}^{p}$ is the deviator component of $\boldsymbol{D}^{p},-D_{v}^{p}$ is the volumetric component of $\boldsymbol{D}^{p}$, and \|\| represents its norms. $\stackrel{\beta}{\boldsymbol{\beta}}$ in Eq. (A1-5) is the Green and Nahdhi's (1965) rate of $\boldsymbol{\beta}$. The parameter groups for the evolution rules in Eqs. (A1-3)-(A1-5) all consists of constants, and from their respective functions we may call $a, b, c, c_{s}$ the degradation indices of structure, $m$ the degradation index of overconsolidation, $b r$ the rotational hardening index, and $m_{b}$ the rotational hardening limit constant.

A new evolution rule for $R^{*}$ is proposed to replace Eq. (A1-3) for expressing structural upgradation, dividing the contribution of plastic deformation to the change of soil structure into the deviator of the plastic stretching $\sqrt{2 / 3} \mathbf{D}_{\mathrm{s}}^{p}$ and volumetric component $-D_{v}^{p}$. The ratio between these terms is given by $c_{\mathrm{s}}\left(0 \leq c_{s} \leq 1\right)$.

\section{The Associated Flow Rule and the Constitutive Equation}

Associated flow rule:

$$
D^{p}=\lambda \frac{\partial f}{\partial T^{\prime}}, \quad \lambda=\frac{\frac{\partial f}{\partial T^{\prime}} \cdot \stackrel{T}{ }^{\prime}}{J \frac{\mathrm{MD}}{p^{\prime}\left(\mathrm{M}^{2}+\eta^{* 2}\right)}\left(\mathrm{M}_{\mathrm{s}}^{2}-\eta^{2}\right)}>0
$$

Constitutive equation: $\stackrel{\circ}{\boldsymbol{T}}^{\prime}=\boldsymbol{E} \boldsymbol{D}-\Lambda \boldsymbol{E} \frac{\partial f}{\partial \boldsymbol{T}^{\prime}}$

$\boldsymbol{E}$ here is the elastic modulus tensor, $\dot{\boldsymbol{T}}^{\prime}$ is the Green and Naghdi's (1965) rate of $\boldsymbol{T}^{\prime}$, and $\Lambda$ is the expression of plastic multiplier $\lambda$ in terms to stretching $\boldsymbol{D}$. Further, we can establish the relations

$$
\begin{aligned}
\mathrm{M}_{s}^{2}= & \mathrm{M}_{a}^{2}+b r \frac{4 \mathrm{M} \eta^{* 2}}{\mathrm{M}^{2}+\eta^{* 2}}\left(m_{b} \eta^{*}-\sqrt{\frac{3}{2}} \hat{\boldsymbol{\eta}} \cdot \boldsymbol{\beta}\right) \\
& -\mathrm{MD}\left(\frac{U^{*}}{R^{*}} 2 \eta^{*}+\frac{U}{R} \sqrt{6 \eta^{* 2}+\frac{1}{3}\left(\mathrm{M}_{a}^{2}-\eta^{2}\right)^{2}}\right)
\end{aligned}
$$

and

$$
\mathrm{M}_{a}^{2}=\mathrm{M}^{2}+\zeta^{2}, \quad \zeta=\sqrt{3 / 2}\|\beta\|
$$

The slope $\mathbf{M}_{s}$ of the threshold between hardening and softening $q=\mathrm{M}_{s} p^{\prime}$, obtained under loading conditions $\lambda>0$, varies according to structural degradation, loss of overconsolidation and development or loss of anisotropy, as well as with the current stress ratio. Similarly, the slope $\mathrm{M}_{a}$ of the threshold between plastic compression and expansion $q=\mathrm{M}_{a} p^{\prime}$ varies in response to the development or loss of anisotropy. For details, the reader is referred to Asaoka et al. (2002). 